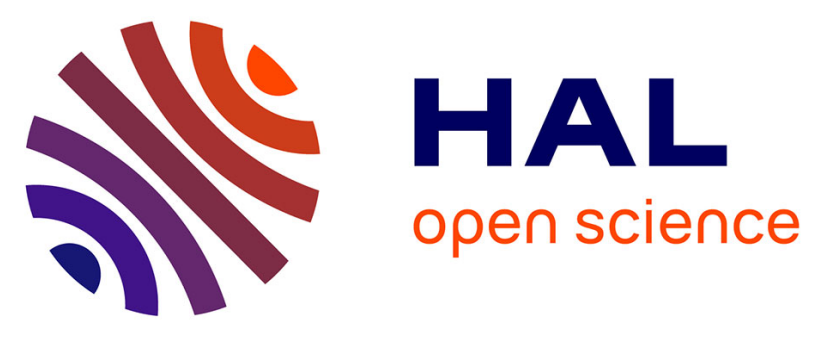

\title{
Shortened telomeres in circulating leukocytes of patients with chronic obstructive pulmonary disease.
}

Laurent Savale, Ari Chaouat, Sylvie Bastuji-Garin, Elisabeth Marcos, Laurent

Boyer, Bernard Maitre, Mourad Sarni, Bruno Housset, Emmanuel

Weitzenblum, Mireille Matrat, et al.

\section{To cite this version:}

Laurent Savale, Ari Chaouat, Sylvie Bastuji-Garin, Elisabeth Marcos, Laurent Boyer, et al.. Shortened telomeres in circulating leukocytes of patients with chronic obstructive pulmonary disease.: telomere length in COPD. American Journal of Respiratory and Critical Care Medicine, 2009, 179 (7), pp.56671. $10.1164 / \mathrm{rccm} .200809-1398 \mathrm{OC}$. inserm-00374870

\section{HAL Id: inserm-00374870 https://www.hal.inserm.fr/inserm-00374870}

Submitted on 10 Apr 2009

HAL is a multi-disciplinary open access archive for the deposit and dissemination of scientific research documents, whether they are published or not. The documents may come from teaching and research institutions in France or abroad, or from public or private research centers.
L'archive ouverte pluridisciplinaire HAL, est destinée au dépôt et à la diffusion de documents scientifiques de niveau recherche, publiés ou non, émanant des établissements d'enseignement et de recherche français ou étrangers, des laboratoires publics ou privés. 


\title{
Shortened Telomeres in Circulating Leukocytes of Patients with Chronic
}

\section{Obstructive Pulmonary Disease}

\author{
Running title: Telomere Length in COPD \\ Laurent Savale $\mathrm{MD}^{1}$, Ari Chaouat $\mathrm{MD}^{2}$, Sylvie Bastuji-Garin $\mathrm{MD} \mathrm{PhD}^{3}$, Elisabeth Marcos $\mathrm{PhD}^{1}$, \\ Laurent Boyer MD ${ }^{1}$, Bernard Maitre $\mathrm{MD}^{4}$, Mourad Sarni MD ${ }^{1}$, Bruno Housset MD ${ }^{4}$, Emmanuel \\ Weitzenblum $\mathrm{MD}^{5}$, Mireille Matrat $\mathrm{MD}^{4}$, Philippe Le Corvoisier $\mathrm{MD}^{7}$, Dominique Rideau ${ }^{1}, \mathrm{~J}$ \\ Boczkowski MD $\mathrm{PhD}^{1}$, Jean-Luc Dubois-Randé $\mathrm{MD}^{1}$, \\ Christos Chouaid $\mathrm{MD}^{6}$, Serge Adnot $\mathrm{MD} \mathrm{PhD}^{1}$
}

Ari Chaouat and Sylvie Bastuji-Garin equally contributed to the study

${ }^{1}$ AP-HP, Hôpital Henri Mondor, INSERM U841 et Service de Physiologie Explorations Fonctionnelles, Université Paris 12, F94010 Créteil, France

${ }^{2}$ CHRU Nancy, Hôpital de Brabois, Service des Maladies Respiratoires et Réanimation Respiratoire, F54511 Vandoeuvre-lès-Nancy, France

${ }^{3}$ AP-HP, Hôpital Henri Mondor, Service de Santé Publique, Université Paris 12, F94010 Créteil, France

${ }^{4}$ Centre Hospitalier Intercommunal de Créteil, Service de Pneumologie et de Pathologie Professionnelle, F94010 Créteil, France

${ }^{5}$ CHRU Strasbourg, Hôpital de Hautepierre, Département de Pneumologie, F67091 Strasbourg, France

${ }^{6}$ AP-HP, Hôpital Henri Mondor, Centre d'Investigation Clinique, F94010 Créteil, France

${ }^{7}$ AP-HP, Hôpital Saint Antoine, Service de Pneumologie, F75571 Paris, France 
Correspondence and requests for reprints should be addressed to Serge Adnot, Hopital Henri Mondor, Service de Physiologie Explorations Fonctionnelles, 94010 Créteil, France. E-mail: serge.adnot@inserm.fr; Tel: +331498126 77; Fax: +33149812667

This study was supported by grants from the INSERM and Délégation à la Recherche Clinique de l'AP-HP. Financial support was received also from the European Commission under the 6th Framework Program (Contract No: LSHM-CT-2005-018725, PULMOTENSION). This publication reflects only the authors' views, and under no circumstances is the European Community liable for any use that may be made of the information it contains.

Running head : telomere length in COPD

\section{Word count: 5432}

\section{Subject code: 53 (COPD: pathophysiology)}

At a glance commentary: Patients with chronic obstructive pulmonary disease (COPD) develop many age-related complications that substantially affect the outcome. COPD is associated with premature aging, suggesting amplification of the mechanisms that underlie aging. Telomere length is considered a marker for biological aging.

What this study adds to the field: Excess telomere shortening was found, supporting accelerated aging in patients with COPD. Decreased telomere length, used as a marker for cellular turnover, exposure to oxidative and inflammatory damage, and biological age, may have clinical significance in COPD. 


\section{Abstract (246)}

Rationale: Telomere length is considered a marker for biological aging. Chronic obstructive pulmonary disease (COPD) may be associated with premature aging.

Objective: To test the hypothesis that patients with COPD experience accelerated telomere shortening and that inflammation is linked to this process.

Methods: We measured telomere length using a quantitative polymerase chain reaction-based method and plasma levels of various cytokines in 136 patients with COPD, 113 age- and sexmatched smokers and 42 nonsmokers with normal lung function.

Measurements and main results: Median [range] telomere length ratio was significantly lower in patients with COPD $(0.57$ [0.23-1.18]) than in control smokers $(0.79$ [0.34-1.58]) or nonsmokers $(0.85[0.38-1.55])(P<0.001)$. The difference remained highly significant using logistic regression analysis adjusted for age, sex, and tobacco exposure. Both females and males with COPD had shorter telomere length than same-sex controls. Telomere length was related to age in patients and controls but was shorter in patients than in controls in all age groups. No relationship was found between telomere length and tobacco exposure in patients or controls, with no difference between control smokers and nonsmokers. In patients with COPD, telomere length was related to arterial PO2 $(P<0.001)$ and PCO2 $(P<0.001)$ but not to lung function parameters or the BODE index. Patients with COPD also had elevated plasma levels of various cytokines, interleukin-6 correlating negatively with telomere length $(P<0.001)$.

Conclusion: Given that in vivo telomere length reflects cellular turnover and exposure to oxidative and inflammatory damage, our data support accelerated aging in COPD.

Keywords: telomere length, COPD, inflammation, hypoxemia 


\section{INTRODUCTION}

Chronic obstructive pulmonary disease (COPD) is becoming increasingly prevalent in most countries and is predicted to become the third leading cause of death worldwide by $2020(1,2)$. Although COPD is primarily a respiratory disease, systemic complications contribute substantially to the prognosis. Most of these systemic complications -- including weight loss, skeletal muscle dysfunction, osteoporosis, and atherosclerosis -- are considered age-related abnormalities (3-5). Osteoporosis and stiffness of the central arteries are increased in patients with COPD compared to age-matched controls, suggesting that COPD may be associated with premature aging related to amplification of the mechanisms that underlie aging $(4,6)$.

Telomere length is considered a biomarker for aging $(7,8)$. Telomeres are DNA sequences and associated proteins that cap and stabilize the ends of linear chromosomes, thereby maintaining genome integrity and stability. Telomere length is not only related to the basic biology of aging as a trigger of cellular senescence, but also reflects the balance between oxidative stress and antioxidant defense mechanisms (9-12). Thus, telomere attrition in circulating white blood cells has been proposed as a marker for cumulative oxidative stress and inflammation and, therefore, as an indicator of the pace of biological aging. Several studies also suggest that telomere shortening may be a risk factor for the development of cancer $(13,14)$, particularly lung cancer $(15,16)$. Moreover, telomere shortening in leukocytes was associated with the development of coronary artery and cerebrovascular disease, and shortening of the age-corrected telomere length was associated with a substantial additional risk of mortality from cardiovascular and infectious diseases $(17,18)$. Patients with COPD are at increased risk for cardiovascular disease and lung cancer, which are the leading causes of death in COPD. Evaluation of telomere length in COPD may therefore be of considerable usefulness, not only to gain further insight into the process of premature aging, but also potentially as a biomarker for disease severity. 
A previous study suggested that telomere length might be shorter in patients with COPD (19), although another found no difference between patients with and without COPD (20). This discrepancy may be ascribable to the small number of patients studied and absence of an appropriate control group matched for age and sex $(19,20)$. Smoking may also affect telomere length (21). However, most comparisons of smokers and nonsmokers failed to include lung function measurements, so that specific effects of smoking could not be assessed independently from those of airflow limitation (21).

In the present study, we measured telomere length in circulating leucocytes from 136 patients with COPD and in 155 age-and sex-matched smokers and nonsmokers with normal lung function. Our goal was to determine whether COPD was associated with reduced telomere length independently from sex, age, and tobacco consumption. We also determined whether lung function parameters and circulating inflammatory cytokine levels were linked to telomere length in patients with COPD and, for some of these factors, in controls. 


\section{METHODS}

\section{Study population}

We studied 136 unrelated patients with COPD recruited at two French centers located in Strasbourg (n=60) and Créteil $(n=76)$, respectively. Inclusion criteria were an at least 10-pack-year history of tobacco smoking and a forced expiratory volume in 1 second (FEV1)/forced vital capacity (FVC) ratio $<70 \%$. Patients were in a stable phase of their disease, defined as no requirement for antibiotic or oral corticosteroid therapy and no change in respiratory symptoms within the last month. Patients were excluded if they had known heart disease, malignancy, or other inflammatory or metabolic conditions. The BODE score was calculated according to Celli et al (22). We also recruited 155 healthy controls (using announcements in local newspapers), including 113 smokers and 42 nonsmokers, who were free of acute or chronic illness except for mild systemic hypertension and whose FEV1 values were $>80 \%$ of predicted and FEV1/FVC ratios greater than 70\%. Screening of controls for study inclusion involved a medical history, clinical examination, electrocardiogram, and comprehensive set of lung function tests. Our initial goal was to recruit 1 age-matched ( \pm 2 years) and sex-matched control per patient but we then included additional individuals to have at least 50 controls with a smoking history greater than 20 pack-years. Nonsmokers were defined as individuals who had never regularly smoked one or more cigarettes a day or who had smoked one or more cigarettes a day for less than 1 year. Smokers were individuals who reported regularly smoking one or more cigarettes a day for at least one year. Former smokers were individuals who reported smoking one or more cigarettes a day regularly in the past but who had not smoked during the last year.

This study was approved by the institutional review board of the Henri Mondor teaching hospital. All patients and controls signed an informed consent document before study inclusion. 


\section{Laboratory investigations}

\section{Measurements of plasma cytokine concentrations in patients and controls}

Plasma samples for measurements of interleukins (IL) IL-6, IL-8, IL-1 $\beta$, monocyte chemotactic protein-1 (MCP-1), transforming growth factor beta (TGF $\beta)$ and tumor necrosis alpha (TNF $\alpha)$ were obtained from all controls and from 103 patients with COPD. Plasma levels of these cytokines were determined using an ELISA (R\&D Systems, Lille, France).

\section{Telomere length assay}

All patients and controls underwent blood sampling for genotype determination. Telomere length was assessed using a real-time quantitative polymerase chain reaction (PCR)-based assay (23). Briefly, the telomere repeat copy number to single-gene copy number (T/S) ratio was determined using an Applied Biosystems 7900HT thermocycler in a 96-well format, using the comparative $\mathrm{Ct}$ method $\left(\mathrm{T} / \mathrm{S}=2^{-\Delta \Delta \mathrm{Ct}}\right)$. Genomic DNA was extracted from blood using the DNeasy Blood Kit (Qiagen, Courtaboeuf, France), and quantified with a spectrophotometer. Each sample was run in triplicate, using the SYBR Green method (Invitrogen, Cergy-Pontoise, France) and $30 \mathrm{ng}$ of DNA. The sequences and final concentrations of the primers for the telomere and 36B4 (acidic ribosomal phosphoprotein $\mathrm{PO}$, a single-copy gene for normalization) were as follows: Tel F, 5'CGGTTtGTTtGGGTTtGGGTTtGGGTTtGGGTTTGGGTT-3', 300 nM; Tel R, 5'-GGCT

TGCCTTACCCTTACCCTTACCCTTACCCTTACCCT-3'， 300 nM; 36B4F， 5'-CAGCA AGTGGGAAGGTGTAATCC-3', 300 nM; and 36B4R, 5'-CCCATTCTATCATCAACGGGTA CAA-3', $300 \mathrm{nM}$. 


\section{Statistical analysis}

The variables compared in COPD patients, control smokers and nonsmokers are listed in Table 1. Qualitative variables are reported as the number (\%), and compared using the Chi-square or Fisher exact test, as appropriate. Quantitative variables are reported as the median [range], except where otherwise indicated, and compared using the nonparametric Kruskal-Wallis test. Most of the quantitative variables were not categorized; however, telomere length was divided according to tertile values defined in the control population and coded 1 when greater than the third tertile, 3 when less than the first tertile, and 2 otherwise. When analysis indicated significance, patients with COPD were compared to smokers and smokers to nonsmokers. Patients and controls were also stratified into age groups to evaluate whether telomere length differences between patients and controls varied with age. To take into account potential associations linking telomere length and/or plasma cytokine levels to pack-year exposure and patients' characteristics, multivariate logistic regression models comparing patients with COPD and controls were built. In these models, telomere length and plasma cytokine levels were $\log _{10}$ transformed and pack-year exposure was expressed by 5 pack-year increments. Multivariate odds ratios (OR) were estimated with their 95\% confidence intervals $(95 \% \mathrm{CI})$. Potential associations between telomere length and physiological or biological variables were separately assessed in patients with COPD or controls using the nonparametric Spearman's rank correlation (Rho). All tests were two-tailed; $P$ values $\leq 0.05$ were considered significant. Data were analyzed using Stata statistical software (StataCorp release 8.0, College Station, TX).

\section{RESULTS}

\section{Clinical characteristics of the study population}

The characteristics of the 136 patients with COPD and 155 controls are reported in Tables 1 and 2. Patients and controls did not significantly differ regarding age, sex, BMI, or systemic arterial 
pressure. All patients were smokers or former smokers, and pack-year exposure was significantly greater in the patients than in the control smokers. Among the 155 controls, 49 were current smokers (pack-year exposure, 30 [2-72]), 64 were former smokers (pack-year exposure, 15 [range 0.5 - 66]), and 42 were nonsmokers. Lung function tests were normal in all controls. Airflow limitation was moderate to severe in the patients (Table 2), and 24 patients were on long-term oxygen therapy at the time of the study.

\section{Telomere length and cytokine plasma levels in patients with COPD and controls}

Telomere length ratios were significantly lower in the patients with COPD 0.57 [.23-1.18] than in the overall control population $0.82[.34-1.58]$ and the control smokers 0.79 [.34-1.58] (Table 1). The telomere shortening in the patients remained significant after adjusting for age, sex, and tobacco exposure using a multivariate logistic model. (Table 1). To better assess whether telomere shortening was an effect of COPD, as opposed to smoking, we performed an additional analysis among smokers ( $\geq 10$ pack-years) by matching patients with COPD to controls on age ( \pm 2 years), sex, and smoking history ( \pm 3 pack-years). This comparison of 50 COPD patients and 50 matched controls showed a highly significant decrease in telomere length in the patients (Table 3). Telomere length within the second tertile had an OR of 15.0 (95\% CI, 2.8-81.7) and within the first tertile of 28.3 (95\% CI, 5.0-159.1). As shown in Figure 1, both females and males with COPD had shorter telomere length values than their same sex controls. Interestingly, telomere length was longer in female controls than in male controls, whereas no difference was noted between male and female patients (Figure 1). Compared to control smokers, patients had significantly increased plasma levels of IL-6, IL-8, IL-1 $\beta$, TNF $\alpha$ and TGF $\beta$ but no significant differences in plasma levels of MCP-1 (Table 1). Within the control group, plasma levels of IL-6, IL-8, MCP-1 and TGF $\beta$ were higher in smokers than in nonsmokers. In contrast, plasma levels of TNF $\alpha$ and IL- $1 \beta$ did not differ between smokers and nonsmokers. 
Relationships between telomere length and physiological and biological variables in patients with COPD and controls

In both patients with COPD and controls, telomere length correlated negatively with age (Table 4). However, telomere length was shorter in the patients than in the controls within each age group (Figure 2). No relationship was found between telomere length and pack-year history in the patients $(\mathrm{Rho}=0.02, P=0.82)$ or the controls $(\mathrm{Rho}=-0.09, \mathrm{p}=0.25)$ whereas a negative correlation was found when patients and controls were combined $(\mathrm{Rho}=-0.37, \mathrm{p}<0.00001)$. Moreover, telomere length in the controls did not differ between smokers and nonsmokers (Table 1). To evaluate whether telomere length was related to COPD severity, we examined the relationships between telomere length and gas exchange parameters, lung-function-test results, and functional indices in the patients. As shown in Table 4 and Figure 3, telomere length showed a strong positive correlation with both $\mathrm{PaO}_{2}$ and $\mathrm{SaO}_{2}$, as well as a negative correlation with $\mathrm{PaCO}_{2}$. No relationship was found between telomere length and FEV1, FVC, DLCO/VA, or the BODE index. Among BODE components, the 6-minute walking distance, which correlated negatively with age $(P<0.001)$, also correlated positively with telomere length. We found no significant difference in telomere length between patients with FEV1 values less than or greater than $50 \%(0.56$ [0.28-1.18] versus 0.60 [0.23-1.16], respectively). Telomere length correlated negatively with IL-6 levels but did not correlate with other cytokine levels in the patients (Table 4). In the controls, only the relationship between telomere length and IL-8 was statistically significant. 


\section{DISCUSSION}

The main finding from this study is that telomere length, as determined in peripheral leukocytes, is markedly decreased in patients with COPD compared to controls, independently from age, sex, and smoking history. Interestingly, telomere length was greater in female controls than in male controls, whereas no sex-related difference was found in the patients. In patients with COPD, telomere length correlated negatively with arterial PO2 and circulating IL-6 levels. Assuming that in vivo telomere length reflects cellular turnover and exposure to oxidative and inflammatory damage, these findings support accelerated aging in patients with COPD and suggest that telomere length may serve as a biomarker in this disease.

We found shorter telomeres in patients with COPD compared to age-matched controls with normal lung function. Telomere length decreased with age in both the patients and the controls but remained shorter in the patients after adjustment for age. The difference between patients and controls also persisted after stratification into age groups, indicating that COPD influenced telomere length at all ages. Telomere length was decreased in both males and females, and telomere length was not greater in the females than in the males of the COPD group, in contradistinction to what was seen in our control group and reported in other studies (24). Thus, COPD was associated with decreased telomere length and also with elimination of the sex-related difference seen in healthy individuals. Because tobacco use may be among the environmental factors that promote telomere shortening and cellular senescence, an important point was whether smoking affected telomere shortening and contributed to the decreased telomere length measured in patients with COPD. We found no relationship between telomere length and tobacco use in either group. Moreover, in the control group, telomere length did not differ between smokers and nonsmokers, or between current smokers, former smokers, and nonsmokers. The multivariate analysis indicated clearly that tobacco use did not affect the relationship between telomere length and COPD and the additional analysis 
comparing 50 patients and 50 controls strictly matched on sex, age and smoking history revealed a highly significant telomere length decrease in the patients. Although these data do not rule out a contribution of smoking to telomere shortening, they indicate that the impact of smoking on telomere length may be small compared to that of COPD. In a previous study including patients with COPD and control smokers, telomere length was affected by smoking but not by COPD (20). The discrepancy with our results may be ascribable to the small number of individuals evaluated in this earlier study and also, possibly, to the higher level of tobacco exposure in the controls, compared to our control group. A negative correlation between pack-years exposure and telomere length was also reported in a large cohort of women (21). In these studies, however, lung-functiontest results were not available and, therefore, the specific effects of tobacco exposure could not be assessed independently from those of airflow limitation. In our study, when both patients and controls were pooled, a significant negative correlation was found between pack-years and telomere length. Thus, our data emphasize the importance of COPD as an independent risk factor for accelerated aging as assessed using telomere length, but they do not rule out a contribution of tobacco exposure.

Among physiological variables, $\mathrm{PaO}_{2}$ showed the strongest link to telomere length in patients with COPD. No direct relationship was found between telomere shortening and the severity of airway obstruction, and some of our patients with mild airway obstruction (FEV1>50\%) had shorter telomeres than controls with normal lung function. The relationship between arterial $\mathrm{PO}_{2}$ and telomere length may be of particular significance, since hypoxia is a known cause of cellular oxidative stress; and patients with COPD experience frequent episodes of oxygen desaturation during sleep, exercise, episodes of acute bronchitis, and COPD exacerbations. Whether treatments aimed at preventing oxygen desaturation and improving arterial oxygenation in patients with COPD may delay this process deserves evaluation. 
COPD may affect telomere length by inducing systemic inflammation. Respiratory tract inflammation in patients with COPD is considered an exaggeration of the normal inflammatory response to chronic irritants such as cigarette smoke (1). A wide variety of inflammatory mediators are increased in the lung and blood of patients with COPD, even those whose clinical status is considered stable (25). Our data are consistent with these well-established concepts, as circulating levels of the pro-inflammatory cytokines IL-6, IL-8, IL-1 $\beta$, and TGF $\beta$ were higher in patients with COPD than in control smokers or nonsmokers. In patients with COPD, IL-6 levels were related to the degree of telomere shortening. The association between IL-6 levels and telomere length is consistent with evidence that oxidative stress and inflammation mediate telomere attrition. In the controls, we also found a tendency for inflammatory markers to correlate with telomere length, although the relationship was significant only for IL-8. It is noteworthy that the inflammatory cytokine levels differed between smokers and nonsmokers whereas telomere length did not. Differences in cytokine levels, however, were much greater between patients with COPD and control smokers than between control smokers and nonsmokers. These results, therefore, do not disagree with the fact that inflammation may affect telomere shortening, however, they suggest a major role for inflammation severity in telomere shortening.

Telomere shortening may be of great significance in patients with COPD. Recent studies suggest that cell senescence may be associated with the pathological process of lung emphysema (26). Senescence of alveolar epithelial and endothelial cells has been shown to be accelerated in emphysematous lungs, and in situ measurements showed decreased telomere length in these cells (26). At present, it is unclear whether telomere dysfunction is a cause or a consequence of COPD. Although decreased telomere length may be viewed as a consequence of cellular turnover and exposure to oxidative and inflammatory damage, the recent observation that telomerase null mice, which experience accelerated aging, also exhibit structural alveolar damage suggests that telomere dysfunction may favor the development of emphysema (27). Our present findings of telomere 
shortening in circulating leukocytes from patients with COPD, are consistent with cellular senescence in COPD being present not only in the lungs but also in other organs. This is of particular interest since cell senescence is considered part of the pathologic process of atherosclerosis $(12,17,28)$. Telomere shortening is strongly associated with increased carotid intima-medial thickness and increased pulse wave velocity, two alterations closely linked to the development of atherosclerosis $(24,29)$. Moreover, there is growing evidence that short telomeres, by inducing chromosome instability, can promote the development of cancer (13). An association between short telomeres and lung cancer has been reported, suggesting that telomere shortening may also be a marker for susceptibility to lung cancer (15). Because lung cancer and cardiovascular events are two major causes of death in patients with COPD, our finding of decreased telomere length in patients with COPD warrants further studies to evaluate the potential prognostic usefulness of telomere length in patients with COPD.

\section{Acknowledgments}

The authors gratefully acknowledge Prof. François Chabot for valuable discussion about the manuscript.

The authors have no conflicts of interest to disclose. 


\section{References}

1. Celli BR, MacNee W. Standards for the diagnosis and treatment of patients with copd: A summary of the ats/ers position paper. Eur Respir J 2004;23:932-946.

2. Murray CJ, Lopez AD. Global mortality, disability, and the contribution of risk factors: Global burden of disease study. Lancet 1997;349:1436-1442.

3. Bolton CE, Ionescu AA, Shiels KM, Pettit RJ, Edwards PH, Stone MD, Nixon LS, Evans WD, Griffiths TL, Shale DJ. Associated loss of fat-free mass and bone mineral density in chronic obstructive pulmonary disease. Am J Respir Crit Care Med 2004;170:1286-1293.

4. Sabit R, Bolton CE, Edwards PH, Pettit RJ, Evans WD, McEniery CM, Wilkinson IB, Cockcroft JR, Shale DJ. Arterial stiffness and osteoporosis in chronic obstructive pulmonary disease. Am J Respir Crit Care Med 2007;175:1259-1265.

5. Sin DD, Man SF. Chronic obstructive pulmonary disease as a risk factor for cardiovascular morbidity and mortality. Proc Am Thorac Soc 2005;2:8-11.

6. Vogelmeier C, Bals R. Chronic obstructive pulmonary disease and premature aging. Am J Respir Crit Care Med 2007;175:1217-1218.

7. Zakian VA. Telomeres: Beginning to understand the end. Science 1995;270:1601-1607.

8. Harley $\mathrm{CB}$, Futcher $\mathrm{AB}$, Greider $\mathrm{CW}$. Telomeres shorten during ageing of human fibroblasts. Nature 1990;345:458-460.

9. Sherr CJ, DePinho RA. Cellular senescence: Mitotic clock or culture shock? Cell 2000;102:407-410.

10. von Zglinicki T, Saretzki G, Docke W, Lotze C. Mild hyperoxia shortens telomeres and inhibits proliferation of fibroblasts: A model for senescence? Exp Cell Res 1995;220:186-193.

11. von Zglinicki T. Oxidative stress shortens telomeres. Trends Biochem Sci 2002;27:339-344. 
12. Matthews C, Gorenne I, Scott S, Figg N, Kirkpatrick P, Ritchie A, Goddard M, Bennett M. Vascular smooth muscle cells undergo telomere-based senescence in human atherosclerosis: Effects of telomerase and oxidative stress. Circ Res 2006;99:156-164.

13. Mathon NF, Lloyd AC. Cell senescence and cancer. Nat Rev Cancer 2001;1:203-213.

14. Campisi J. Cancer and ageing: Rival demons? Nat Rev Cancer 2003;3:339-349.

15. Jang JS, Choi YY, Lee WK, Choi JE, Cha SI, Kim YJ, Kim CH, Kam S, Jung TH, Park JY. Telomere length and the risk of lung cancer. Cancer Sci 2008;99:1385-1389.

16. Perera SA, Maser RS, Xia H, McNamara K, Protopopov A, Chen L, Hezel AF, Kim CF, Bronson RT, Castrillon DH, et al. Telomere dysfunction promotes genome instability and metastatic potential in a k-ras p53 mouse model of lung cancer. Carcinogenesis 2008;29:747-753.

17. Brouilette SW, Moore JS, McMahon AD, Thompson JR, Ford I, Shepherd J, Packard CJ, Samani NJ. Telomere length, risk of coronary heart disease, and statin treatment in the west of scotland primary prevention study: A nested case-control study. Lancet 2007;369:107-114.

18. Cawthon RM, Smith KR, O'Brien E, Sivatchenko A, Kerber RA. Association between telomere length in blood and mortality in people aged 60 years or older. Lancet 2003;361:393-395. 19. Houben JM, Mercken EM, Ketelslegers HB, Bast A, Wouters EF, Hageman GJ, Schols AM. Telomere shortening in chronic obstructive pulmonary disease. Respir Med 2008.

20. Morla M, Busquets X, Pons J, Sauleda J, MacNee W, Agusti AG. Telomere shortening in smokers with and without COPD. Eur Respir J 2006;27:525-528.

21. Valdes AM, Andrew T, Gardner JP, Kimura M, Oelsner E, Cherkas LF, Aviv A, Spector TD. Obesity, cigarette smoking, and telomere length in women. Lancet 2005;366:662-664.

22. Celli BR, Cote CG, Marin JM, Casanova C, Montes de Oca M, Mendez RA, Pinto Plata V, Cabral HJ. The body-mass index, airflow obstruction, dyspnea, and exercise capacity index in chronic obstructive pulmonary disease. N Engl J Med 2004;350:1005-1012.

23. Cawthon RM. Telomere measurement by quantitative pcr. Nucleic Acids Res 2002;30:e47. 
24. Benetos A, Okuda K, Lajemi M, Kimura M, Thomas F, Skurnick J, Labat C, Bean K, Aviv A. Telomere length as an indicator of biological aging: The gender effect and relation with pulse pressure and pulse wave velocity. Hypertension 2001;37:381-385.

25. Gan WQ, Man SF, Senthilselvan A, Sin DD. Association between chronic obstructive pulmonary disease and systemic inflammation: A systematic review and a meta-analysis. Thorax 2004;59:574-580.

26. Tsuji T, Aoshiba K, Nagai A. Alveolar cell senescence in patients with pulmonary emphysema. Am J Respir Crit Care Med 2006;174:886-893.

27. Lee J, Reddy R, Barsky L, Scholes J, Chen H, Shi W, Driscoll B. Lung alveolar integrity is compromised by telomere shortening in telomerase-null mice. Am J Physiol Lung Cell Mol Physiol 2009;296:L57-70.

28. Minamino T, Miyauchi H, Yoshida T, Ishida Y, Yoshida H, Komuro I. Endothelial cell senescence in human atherosclerosis: Role of telomere in endothelial dysfunction. Circulation 2002;105:1541-1544.

29. O'Donnell CJ, Demissie S, Kimura M, Levy D, Gardner JP, White C, D'Agostino RB, Wolf PA, Polak J, Cupples LA, et al. Leukocyte telomere length and carotid artery intimal medial thickness: The framingham heart study. Arterioscler Thromb Vasc Biol 2008;28:1165-1171. 


\section{Figure legends}

Figure 1: telomere length in females and males among controls and patients with COPD. Comparisons were adjusted for age and pack-years. Values are median [interquartile range]. The bars represent the extreme values.

Figure 2: Telomere length in controls and patients with COPD in each 10-year age group. Comparisons were adjusted for sex and pack-years Values are median [interquartile range]. The bars represent the extreme values.

Figure 3: Correlations between telomere length, $\mathrm{PaO} 2(\mathrm{Rho}=0.27, \mathrm{p}<0.002)$ and $\mathrm{PaCO} 2(\mathrm{Rho}=-$ $0.26, \mathrm{p}<0.02)$ in patients with COPD. 
Table 1. Comparison of physiological and biological variables between patients with chronic obstructive pulmonary disease and controls (smokers and nonsmokers)

\begin{tabular}{|c|c|c|c|c|c|c|}
\hline & \multirow{2}{*}{$\begin{array}{l}\text { Patients } \\
(\mathrm{n}=136)\end{array}$} & \multicolumn{2}{|c|}{ Controls $(\mathrm{n}=155)$} & \multirow[t]{2}{*}{$\mathrm{P}$ value* } & \multicolumn{2}{|c|}{$\begin{array}{l}\text { Adjusted analysis (patients versus } \\
\text { controls) } \dagger\end{array}$} \\
\hline & & $\begin{array}{c}\text { Smokers } \\
(\mathrm{n}=113) \\
\end{array}$ & $\begin{array}{c}\text { Nonsmokers } \\
(\mathrm{n}=42)\end{array}$ & & OR $[95 \% \mathrm{CI}]$ & $\mathrm{P}$ value \\
\hline Females/males & $33 / 103$ & $32 / 81$ & $15 / 27$ & 0.34 & - & - \\
\hline Age, $y$, mean $\pm S D$ & $62.9 \pm 6.6$ & $62.2 \pm 7.7$ & $61.4 \pm 6.1$ & 0.07 & - & - \\
\hline BMI, kg/m² & $25.6[14.2-42.7]$ & $25.6[19.5-47.0]$ & $25.4[20.7-45.3]$ & 0.69 & - & - \\
\hline MAP, mmHg & $96.7[68.3-125.3]$ & $99.3[75-140]$ & $98.3[79.3-130]$ & 0.51 & - & - \\
\hline $\mathrm{FEV}_{1}, \%$ pred & $38.4[13.3-90.7]^{\ddagger}$ & $94.0[81.0-128]$ & $98[81.0-135]$ & 0.0001 & & \\
\hline $\mathrm{FEV}_{1}, \mathrm{~L}$ & $1.01[0.3-3.12]^{*}$ & $2.86[1.24-4.42]$ & $2.76[0.97-4.40]$ & 0.0001 & & \\
\hline $\mathrm{FVC}, \%$ pred & $72.8[29.3-131]^{\sharp}$ & $103[75.0-118]$ & $101[84.0-129]$ & 0.0001 & & \\
\hline FVC, $\mathrm{L}$ & $2.21[0.80-5.4]^{\ddagger}$ & $3.65[1.75-5.77]$ & $3.70[1.78-5.96]$ & 0.0001 & & \\
\hline $\mathrm{FEV}_{1} / \mathrm{FVC}$ & $45.6[19.7-69.0]^{\ddagger}$ & $77.0[71.0-99.4]$ & $76.3[71.0-99.4]$ & 0.0001 & & \\
\hline Pack-years & $48[10-180]^{\ddagger}$ & $22[0.5-72]$ & $0 \pi$ & 0.0001 & $1.47[1.35-1.61]^{\S}$ & .000 \\
\hline Telomere length ( $\mathrm{T} / \mathrm{S}$ ratio) & $0.57[0.23-1.18]^{\ddagger}$ & $0.79[0.34-1.58]$ & $0.85[0.38-1.55]$ & 0.0001 & $.0001\left[10^{-5}-.001\right]^{\#}$ & .000 \\
\hline IL-6, pg/ml & $2.4[.3-30.5]^{\ddagger}$ & $1.5[.5-15.3]$ & $0.9[0.1-3.6]^{9}$ & 0.0001 & $5.17[1.73-15.47]^{\#}$ & .003 \\
\hline $\mathrm{MCP}-1, \mathrm{pg} / \mathrm{ml}$ & $475[126-1274]$ & 468 [304-769] & $394[111-779]^{\pi}$ & 0.0006 & $8.12[1.05-63.06]$ & 0.05 \\
\hline IL-8, pg/ml & $12.4[.9-36.6]^{*}$ & $9.6[3.6-37.6]$ & $8.3[2.2-19.2]^{\pi}$ & 0.0001 & $3.82[.90-16.20]^{\#}$ & .069 \\
\hline $\mathrm{IL}-1 \beta, \mathrm{pg} / \mathrm{ml}$ & $0.63[0.1-3.5]^{\ddagger}$ & $0.34[0.1-2.28]$ & $0.24[0.06-1.4]$ & 0.0001 & $5.23[.91-30.21]^{\#}$ & .065 \\
\hline
\end{tabular}




\begin{tabular}{|c|c|c|c|c|c|c|}
\hline $\mathrm{TGF} \beta, \mathrm{pg} / \mathrm{ml}$ & $28.9[4.3-55.5]^{*}$ & $18.3[5.9-38.2]$ & $16.4[9.1-24.3]^{9}$ & 0.0001 & $94.93[8.74-1030.5]^{\#}$ & .000 \\
\hline $\mathrm{TNF} \alpha, \mathrm{pg} / \mathrm{ml}$ & $1.8[0.2-10.9]^{\ddagger}$ & $1.5[0.1-12.2]$ & $1.6[0.5-5.0]$ & 0.08 & $1.59[.33-7.68]^{\#}$ & .56 \\
\hline
\end{tabular}

Abbreviations: OR, odds ratio; CI, confidence interval; BMI, body mass index; MAP, mean arterial pressure; FEV1, forced expiratory volume in 1 second; \% pred, percentage of the predicted value; FVC, forced vital capacity; IL-6, interleukin-6; MCP-1, monocyte chemotactic protein-1; IL-8, interleukin-8; IL-1 $\beta$, interleukin-1 $\beta$; TGF $\beta$, transforming growth factor beta; TNF $\alpha$, tumor necrosis factor alpha.

Data are presented as medians [range] unless stated otherwise.

* P value of the Chi-square test, Fisher exact test or of the non parametric Kruskal-Wallis test as appropriate comparing the 3 populations (Patients, smoker's and non-smoker's controls).

$\dagger$ Odds ratios, with 95\% confidence intervals estimated by unconditional logistic regression analysis adjusted for age, sex, and number of pack-years.

${ }^{\S}$ OR expressed for an increase of 5 Pack-years

${ }^{\#}$ OR expressed for a change of one unit of measurement after $\log _{10}$ transformation

$\mathrm{P} \leq 0.05$ for the comparisons between "patients and smokers' controls and between "Ismokers' and nonsmokers' controls (Kruskal-Wallis test) 
Table 2. Other characteristics of the 136 patients with chronic obstructive pulmonary disease

\begin{tabular}{lccc}
\hline & $\mathrm{N}$ & Median value & [Range] \\
\hline Dyspnea score & 107 & 3 & {$[0-5]$} \\
6-min. walking distance, $\mathrm{m}$ & 115 & 400 & {$[80-620]$} \\
$\mathrm{BODE}$ index & 96 & 4 & {$[0-10]$} \\
$\mathrm{Hb}, \mathrm{g} / \mathrm{dl}$ & 135 & 14.1 & {$[9.9-21.3]$} \\
$\mathrm{DLCO} / \mathrm{VA}, \%$ pred & 82 & 67.2 & {$[20.4-135]$} \\
$\mathrm{PaO}_{2}, \mathrm{~mm} \mathrm{Hg}$ & 136 & 65.1 & {$[46.4-103]$} \\
$\mathrm{PaCO}_{2}, \mathrm{~mm} \mathrm{Hg}$ & 136 & 42.1 & {$[30.8-66.0]$} \\
$\mathrm{SaO}_{2}, \%$ & 136 & 93.4 & {$[76.2-98.5]$} \\
\hline
\end{tabular}

Dyspnea score : MRC score; BODE Index: Body Mass Index, Airflow obstruction, Dyspnea, and Exercise Capacity Index; Hb, hemoglobin; DLCO: diffusion capacity of the lung for carbon monoxide; VA: alveolar ventilation; $\mathrm{PaO} 2$, arterial oxygen partial pressure; $\mathrm{PaCO} 2$, arterial carbon dioxide partial pressure; $\mathrm{SaO} 2$, oxygen saturation of arterial blood. Blood gases were analyzed from arterial blood samples. 
Table 3. Comparison of telomere length in 50 patients with chronic obstructive pulmonary disease and 50 controls matched for sex, age $( \pm 2$ years) and smoking history $( \pm 3$ pack-years $)$

\begin{tabular}{|c|c|c|c|c|c|}
\hline & Patients & Controls & $\mathrm{P}$ value $*$ & \multicolumn{2}{|c|}{ Adjusted analysis $\dagger$} \\
\hline & $\mathrm{N}=50$ & $\mathrm{~N}=50$ & & OR $[95 \% \mathrm{CI}]$ & $\mathrm{P}$ \\
\hline Male/Female & $35 / 15$ & $35 / 15$ & 1 & & \\
\hline Age (years) & $59[49-76]$ & $59[50-78]$ & 0.69 & & \\
\hline Pack-years & $35[10-75]$ & $34[10-72]$ & 0.79 & & \\
\hline Telomere length $\mathrm{T} / \mathrm{S}$ ratio & $0.58[0.23-1.18]$ & $0.76[0.42-1.19]$ & 0.0001 & $0.00001\left[0.810^{-7}-0.002\right]^{\#}$ & 0.000 \\
\hline$\geq 3^{\text {rd }}$ tertile $(.85), \mathrm{n}(\%)$ & $2(4.0)$ & $17(34.0)$ & & 1 & \\
\hline$] 3^{\text {rd }}-1^{\text {st }}$ tertile] $(.63-.85)$ & $18(36.0)$ & $16(32.0)$ & & $15.0[2.8-81.7]$ & 0.002 \\
\hline$<1^{\text {st }}$ tertile $(.63)$ & $30(60.0)$ & $17(34.0)$ & 0.000 & $28.2[5.0-159.1]$ & 0.000 \\
\hline
\end{tabular}

Data are presented as medians [range] unless stated otherwise.

*P value of the non parametric Kruskal-Wallis test or the Fisher exact test as appropriate.

$\dagger$ Odds ratios, with $95 \%$ confidence intervals estimated by unconditional logistic regression analysis adjusted for age, sex, and number of packyears.

${ }^{\#}$ OR expressed for a change of one unit of measurement after $\log _{10}$ transformation. 
Table 4. Correlations between telomere length and other variables in patients with chronic obstructive pulmonary disease and in controls with normal lung function

\begin{tabular}{|c|c|c|c|c|}
\hline & \multicolumn{2}{|c|}{ COPD patients } & \multicolumn{2}{|c|}{ Control patients } \\
\hline & Spearman's Rho & $\mathrm{P}$ value & Spearman's Rho & $\mathrm{P}$ value \\
\hline Age, $y$ & -0.175 & .042 & -0.29 & 0.0003 \\
\hline Pack-years & 0.02 & 0.82 & -0.09 & 0.25 \\
\hline $\mathrm{FEV}_{1}, \%$ & 0.03 & 0.75 & 0.04 & 0.66 \\
\hline $\mathrm{FEV}_{1}, \mathrm{~L}$ & 0.08 & 0.38 & 0.03 & 0.71 \\
\hline FVC, L & 0.11 & 0.22 & 0.01 & 0.90 \\
\hline $\mathrm{FEV}_{1} / \mathrm{FVC}$ & 0.009 & 0.91 & 0.10 & 0.24 \\
\hline $\mathrm{PaO}_{2}, \mathrm{~mm} \mathrm{Hg}$ & 0.27 & 0.002 & - & \\
\hline $\mathrm{PaCO}_{2}, \mathrm{~mm} \mathrm{Hg}$ & -0.26 & 0.002 & - & \\
\hline $\mathrm{SaO} 2$ & 0.25 & 0.004 & & \\
\hline BODE index & -0.07 & 0.48 & - & \\
\hline 6-min. walking distance & 0.24 & 0.009 & - & \\
\hline IL-6, pg/ml & -0.27 & 0.005 & -0.11 & 0.18 \\
\hline IL-8, pg/ml & -0.02 & 0.84 & -0.21 & 0.012 \\
\hline $\mathrm{IL}-1 \beta, \mathrm{pg} / \mathrm{ml}$ & -0.07 & 0.56 & -0.13 & 0.22 \\
\hline $\mathrm{TGF} \beta, \mathrm{pg} / \mathrm{ml}$ & 0.023 & 0.84 & -0.14 & 0.11 \\
\hline $\mathrm{TNF} \alpha, \mathrm{pg} / \mathrm{ml}$ & 0.005 & 0.96 & -0.03 & 0.67 \\
\hline $\mathrm{MCP}-1, \mathrm{pg} / \mathrm{ml}$ & -0.12 & 0.21 & 0.12 & 0.14 \\
\hline
\end{tabular}


FEV1: forced expiratory volume in 1 second; $\mathrm{FVC}$, forced vital capacity; $\mathrm{PaO}_{2}$, arterial oxygen partial pressure; $\mathrm{PaCO}_{2}$, arterial carbon dioxide partial pressure; $\mathrm{SaO}_{2}$, oxygen saturation of arterial blood; BODE Index: Body Mass Index, Airflow Obstruction, Dyspnea, and Exercise Capacity Index; IL, interleukin; TGF $\beta$, transforming growth factor beta; TNF $\alpha$, tumor necrosis factor alpha; MCP-1, monocyte chemotactic protein-1 
Figure 1

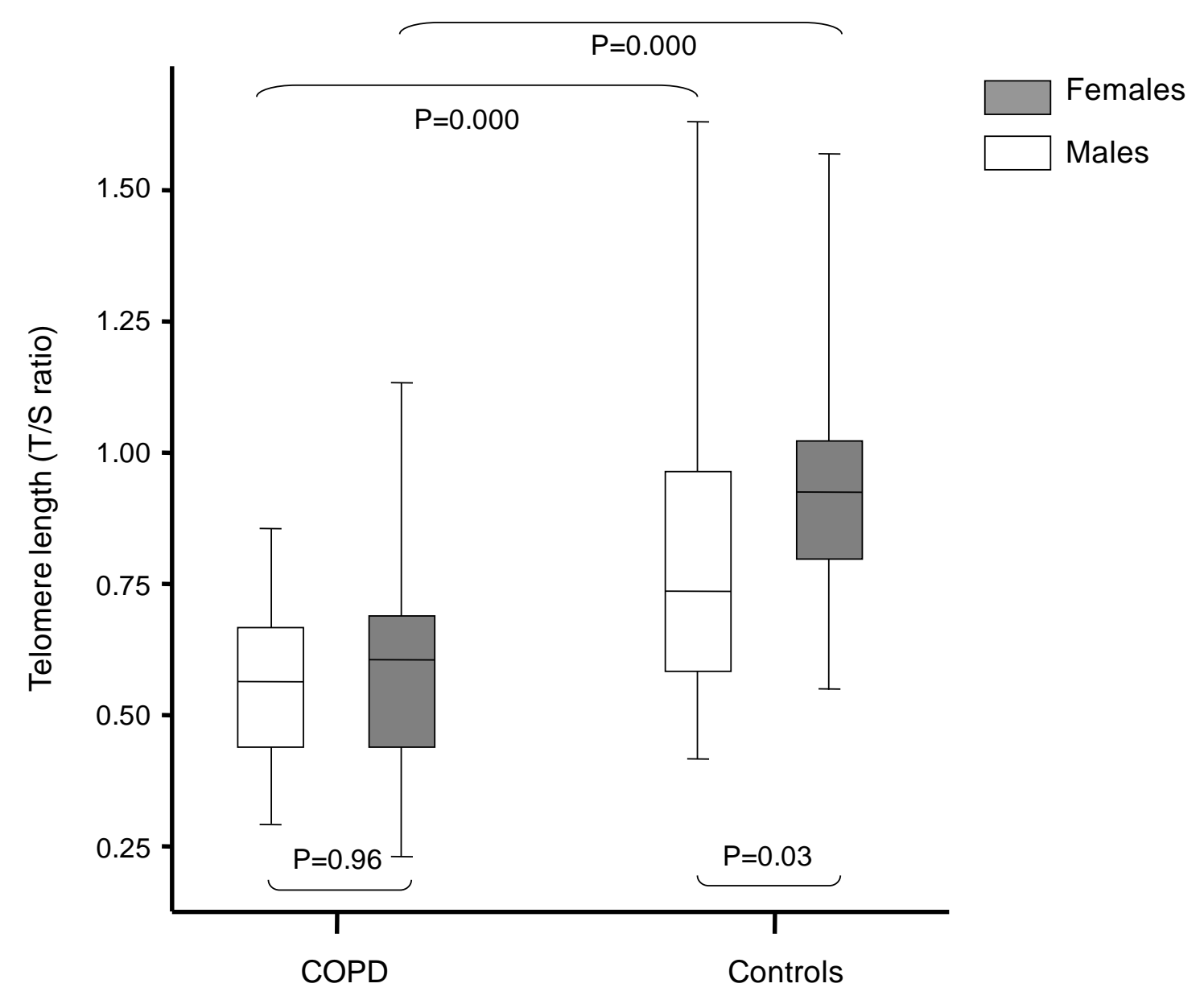


Figure 2

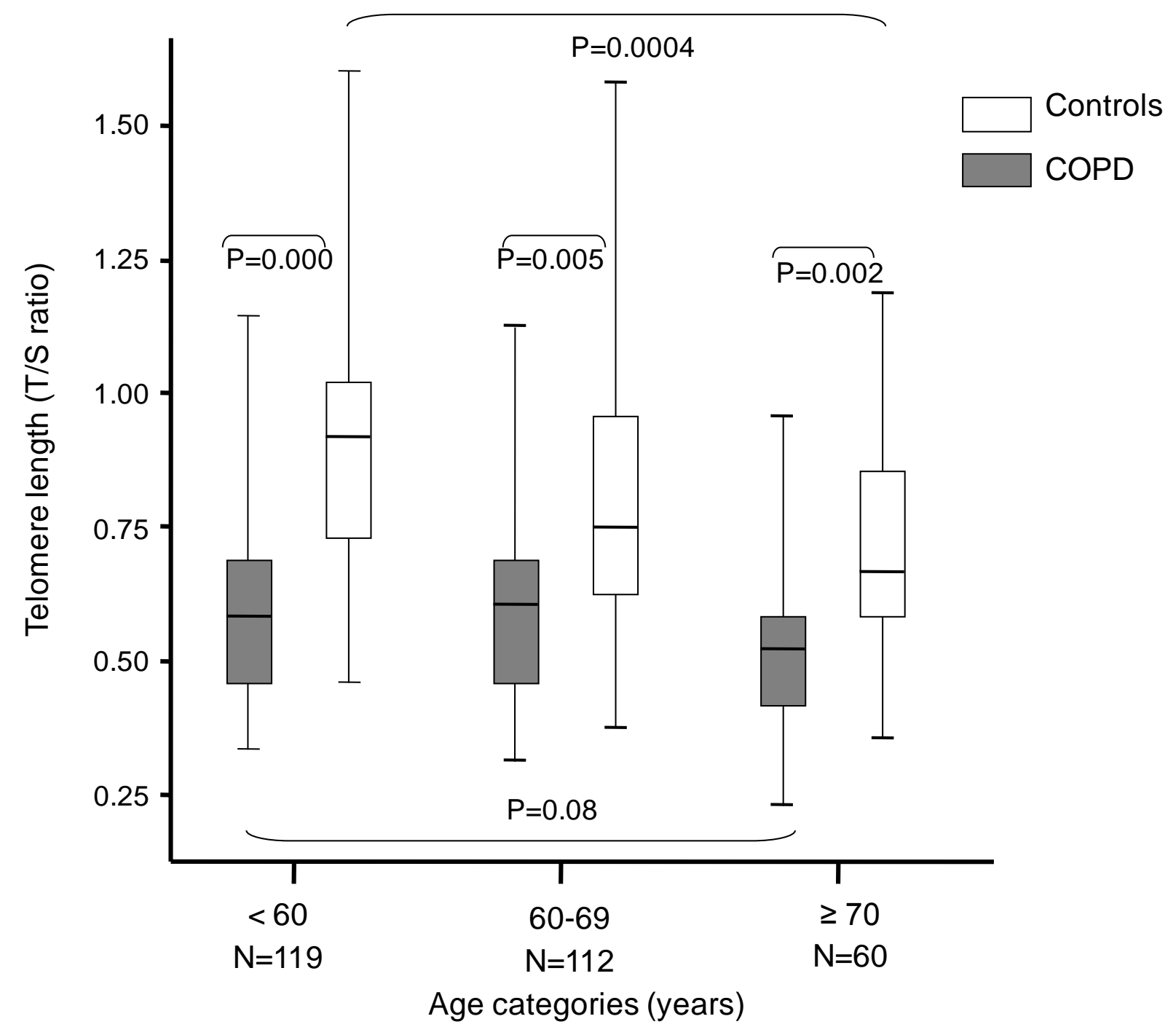


Figure 3
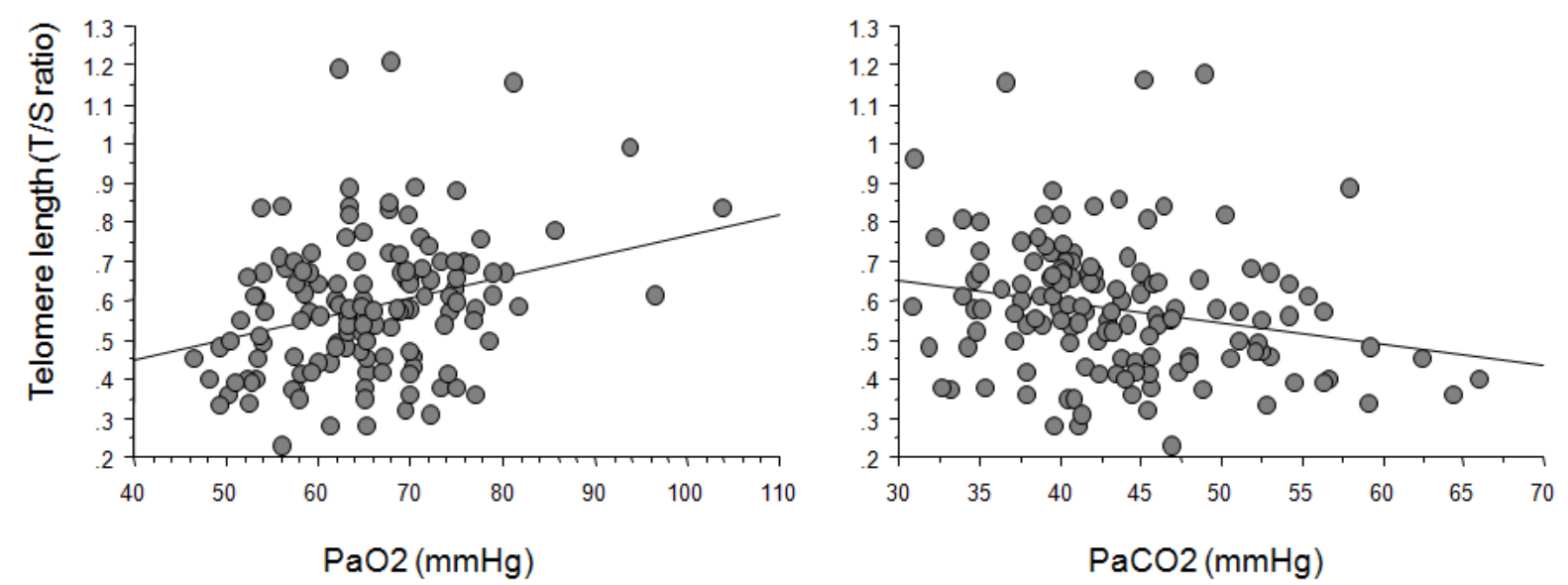